\title{
Effects of Elastic Modulus on Behavior of Polymer Coated Fiber Modified Short Concrete Beams
}

\author{
Kasim Korkmaz ${ }^{1, ~ *, ~ S a l i h ~ K o c a k ~}{ }^{2}$, Mohamed El Gafy ${ }^{3}$, Erkan Boztas ${ }^{1}$ \\ ${ }^{1}$ School of Visual and Built Environments, Eastern Michigan University, Ypsilanti, USA \\ ${ }^{2}$ Building Construction, University of West Florida, Pensacola, USA \\ ${ }^{3}$ School of Planning, Design, and Construction, Michigan State University, East Lansing, USA
}

\section{Email address:}

kkorkmaz@emich.edu (K. Korkmaz)

${ }^{*}$ Corresponding author

\section{To cite this article:}

Kasim Korkmaz, Salih Kocak, Mohamed El Gafy, Erkan Boztas. Effects of Elastic Modulus on Behavior of Polymer Coated Fiber Modified Short Concrete Beams. American Journal of Construction and Building Materials. Vol. 3, No. 1, 2019, pp. 1-9. doi: 10.11648/j.ajcbm.20190301.11

Received: October 14, 2018; Accepted: November 1, 2018; Published: January 29, 2019

\begin{abstract}
Polymers have been one of the mostly and effectively used materials all over the world recently. They have been gaining popularity for various purposes in the concrete industry last couple of decades as well. They have the ability to increase the strength and durability of the concrete products. Moreover, polymers in concrete industry can also be considered as a sustainable product since they achieve the requirements of the consumers without adversely affecting the environment, health and the economy. Fiber-modified short beams are structural members commonly used in construction industry. To enhance their physical properties, various methods have been developed; however, most of them have been considered costly and time consuming. In this study, it was concluded that one major physical property, strength, of fiber-modified concrete short beams could be improved by using polymer as a coating material. Hence, the capacity and probably the service life of those beams could be improved. Furthermore, proper polymer coating may reduce the maintenance costs. In this study, polymer coating is applied for fiber modified short concrete beams. The change in modulus of elasticity was investigated as the identifying parameter between various coated short beams since it is an important parameter in the design and analysis processes of the beams. The elastic moduli for various regions of the world were derived from compressive strength results. The maximum deflection values were computed for each region and each polymer coating as well. Finally, the most effective polymer type and coating were discovered according to the maximum deflections obtained for simply supported beam approach.
\end{abstract}

Keywords: Fiber-Modified Short Beams, Polymers, Modulus Elasticity, Structural Behavior

\section{Introduction}

Concrete is a mixture of Portland cement, water, fine and coarse mineral aggregates, and admixtures to facilitate the some hardened and fresh properties. When all the materials are mixed in the correct proportions, a complex chemical reaction takes place. This reaction is known as the cement hydration and at the end concrete hardens and gets ready for curing [1]. Concrete deteriorates over time. When concrete is subjected to external loads, micro cracks may develop inside the concrete and then propagate. Concrete service life decreases due to these internal cracks and extra porosity created. Water can easily infiltrate from the surface cracks and captured inside the concrete. Once the freezing temperatures are encountered, water freezes causing volume expansion and ultimately damaging the concrete. Therefore, concrete preservation and maintenance have been an important topic especially for the last couple of decades.

Polymers consist of molar masses and long repeating chains of molecules. They have unique properties and these properties alter depending on the molecule type and the structure how the molecules are bonded together. They can be natural and synthetic. Teflon, nylon, epoxy, Kevlar fall into synthetic polymers class while proteins, starches, cellulose and latex can be classified as natural polymers. 
Even though both synthetic and natural polymers used in the construction industry, the trend is toward the use of synthetic polymers since they can be engineered according to the specific requirements of the construction projects. Some hardening polymers could be used as a life treatment agent in concrete preservation. Their goal is to enhance the resistance of concrete to environmental and load related impacts. Polymer coating is seen as a suitable method for concrete preservation $[2,3]$. Optimal amount of polymer coating may be the solution for concrete preservation by increasing the structural strength of fiber-modified concrete without adversely affecting the life cycle coast.

Concrete is the second most consumed product in the world behind the water. Each year 12 billion tons of concrete is produced worldwide. This makes the concrete one of the most important construction materials all over the world. [4, 5] It is used for all types of construction, including infrastructures and superstructures. The need for hardened construction materials goes back into ancient times. People used to mix soil, stone, sand and water at various combinations to form hardened constructions. By the discovery of Portland cement at early 1800s and industrial revolution, the use of concrete quickly became widespread. Despite its low tensile strength capacity, which is around $11 \%$ of its compressive strength, concrete has been number one construction material for decades. Concrete structures can be exposed to numerous structural and environmental conditions, such as; earthquakes, abrasion, humidity, freeze and thaw, heat, wind load, snow load, during its life cycle. Once the mix design of the concrete is decided and it is poured, one of the ways to increase its durability and the strength may be polymer coating. Polymer coatings also help to protect the concrete surface to prevent water ingress from capillary pores $[6,7]$.

The elastic modulus of concrete is an essential parameter for the evaluation of structural stiffness, deflection and it is also a fundamental property required for the appropriate analysis and design of reinforced concrete structures. Various formulations to calculate elastic moduli are available in different national codes. Calculated elastic moduli values for the same concrete strength vary according to different codes' origins resulting from different observations in experimental research. Therefore, lateral displacement and story-drift calculations using elastic moduli formulations in national codes may differ from the code requirements. A new method to define elastic moduli is needed. This new definition would result in more dependable story drift calculations to meet code requirements, and likewise to produce more dependable structural designs.

\section{Polymer Effect on Beam Behavior}

It is generally wise approach and preferable method of preservation and maintenance to protect the concrete, or any other material, before it is damaged. Even though the concrete does not show any damage on its surface, it might have internal problems, which shortens its life considerably. Polymer impregnation (PI) conducted by researchers in showed that PI on the concrete samples with internal cracks increased the durability of the concrete $[8,9]$. The previous studies, such as PI, and the need for a better concrete preservation method became the main motivation for this research work. In this study, five different types of polymers have been applied as coating material onto the beams. Coating process started once the 28-day curing period was completed. The application of the polymer was performed using a roller brush as shown in Figure 1. Each side of the concrete beam was coated with the same amount of liquid polymer. The coating was performed on top of the scale. The weight was recorded following each pass of the roller brush to ensure that all faces of the samples would have the same amount of polymer coating, The impact of elastic modulus on the polymer coated fiber reinforced concrete beams were investigated.

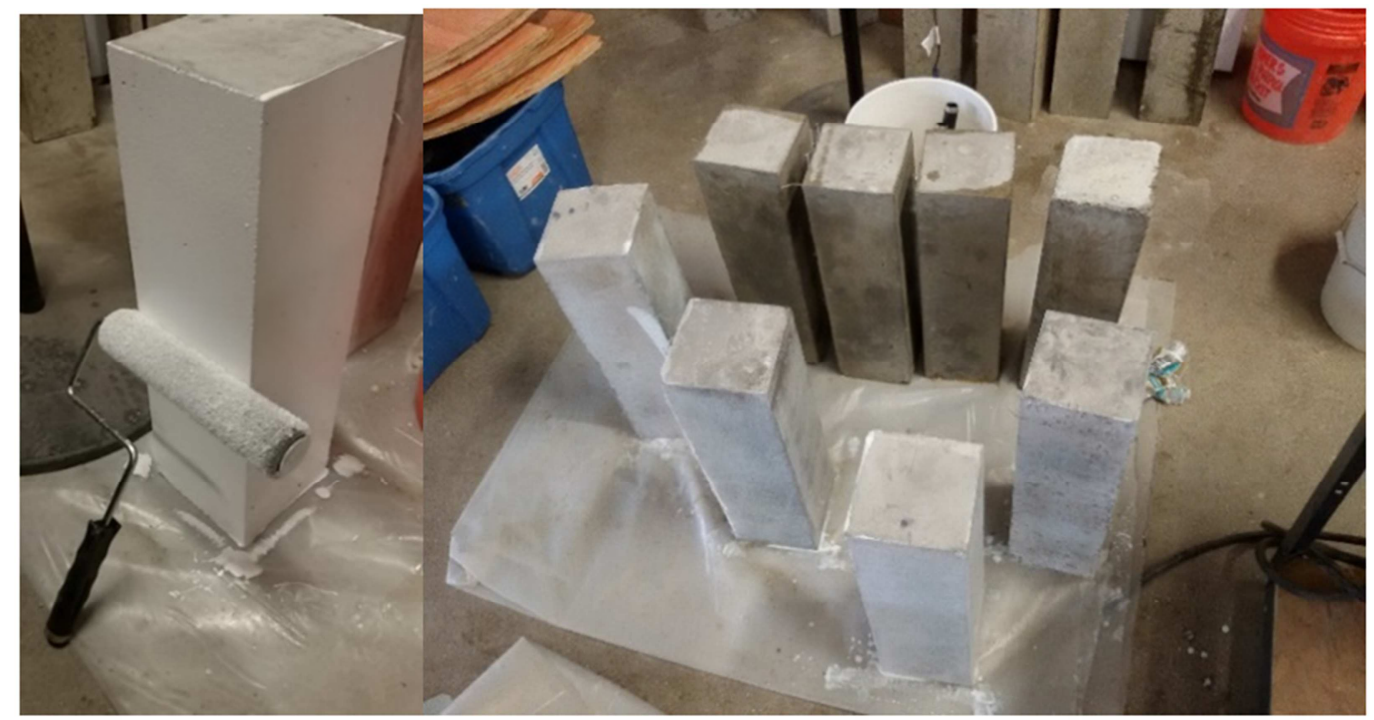

Figure 1. Pictures of a Fiber Reinforced Concrete Beam after the Application of Liquid Polymer Coating. 


\section{Modulus of Elasticity $\left(E_{c}\right)$}

Ideally, the elastic modulus of concrete is calculated using the measurement from samples under compressive strength test by recording the load-deformation curve. However, it is not always the way to find the elastic modulus of concrete. The testing setup for measuring the deformations under the applied compressive load is very time consuming and requires precise, complicated and expensive testing extensions compared to the basic compressive strength measurements. Hence, in order to avoid the demanding and lengthy direct measurements for the elastic modulus (Ec), researchers attempt to predict concrete's elastic modulus using either a theoretical or an empirical approach. In the latter case, which is most commonly used, the elastic modulus is usually expressed as function of compressive strength [10-12]. Different countries apply different formulas to calculate the modulus of elasticity of the concrete $[13,14]$. Empirical models to estimate the modulus of elasticity for different countries were gathered from their codes and listed in Table 1.

The empirical approaches estimate the elastic modulus fairly well. It is mainly because of the successful measurement of compressive strength values. Eight-country or union codes were studied to find the elastic modulus as a function of compressive strength. Europe and the States have more than one code to estimate the modulus of elasticity. Hence, ten different codes were compared in total. The compressive strength of concrete was obtained according to ASTM C-39 standard test method for compressive strength of cylindrical concrete specimens. There were six (6) $15 \mathrm{~cm}$ in diameter by $30 \mathrm{~cm}$ in height cylindrical samples (cross sectional area of $176.72 \mathrm{~cm}^{2}$ ) prepared and tested. The curing of the samples was achieved by submerging the samples in a temperature controlled water bath at $23.5^{\circ} \mathrm{C}$. The average 28 day compressive strength of the laboratory prepared concrete specimens was computed as $36.00 \mathrm{MPa}$. Moreover, standard deviation and coefficient of variation of the tested samples were calculated to ensure the proper sample preparation and repeatability of the concrete mixture, sample preparation, curing and testing procedures. Table 2 exhibits the load at failure and compressive strength of each of six samples along with the average compressive strength, standard deviation and coefficient of variation (COV).

Table 1. Changes in Modulus of Elasticity in Different Countries.

\begin{tabular}{ll}
\hline Code & Modulus of elasticity (MPa) \\
\hline USA, ACI 318 & $E c=4700 \times \sqrt{f c}$ \\
USA, ACI 363 & $E c=3300 \times \sqrt{f c}+6900$ \\
Turkey & $E c=3200 \times \sqrt{f c}+14000$ \\
China & $E c=\frac{10^{5}}{2.2+34.7 / f c}$ \\
India & $E c=5000 \times \sqrt{f c}$ \\
Europe, Euro Code & $E c=9500 \times f c^{1 / 3}$ \\
Europe, CEB-FIB & $E c=10000 \times(f c+8)^{1 / 3}$ \\
Canada & $E c=3300 \times \sqrt{f c}+6900$ \\
Great Britain & $E c=200 \times f c+20000$ \\
Mexico & $E c=4400 \times \sqrt{f c}$ \\
\hline
\end{tabular}

Table 2. 28-Day Compressive Strength Calculation.

\begin{tabular}{|c|c|c|c|}
\hline \multicolumn{4}{|c|}{28 -Day Compressive Strength of Concrete Samples (MPa) } \\
\hline Sample Number & Load at Failure (kN) & Compressive Strength (MPa) & Average Compressive Strength (MPa) \\
\hline 1 & 623 & 35.90 & \multirow{6}{*}{36.00} \\
\hline 2 & 630 & 35.98 & \\
\hline 3 & 622 & 35.86 & \\
\hline 4 & 628 & 36.24 & \\
\hline 5 & 621 & 35.83 & \\
\hline 6 & 628 & 36.21 & \\
\hline \multicolumn{3}{|l|}{ Standard Deviation } & 0.18 \\
\hline \multicolumn{3}{|c|}{ Coefficient of Variation (\%) } & 0.50 \\
\hline
\end{tabular}

The compressive strength value obtained for fiber reinforced cylindrical samples was used in the computation of the modulus of elasticity throughout the research. With various samples, investigation has been carried out for various design codes. As expected, once compressive strength of the concrete increases, modulus of elasticity values rise. This holds true for the rigidity and stiffness. Concrete with a higher elastic modulus will be stiffer and less prone to the deflections for the beams [15-17]. Therefore, higher elastic modulus values will be preferable in the design 
of concrete structures, since concrete with higher elastic modulus will tend to deflect less than concrete with a lower elastic modulus value. However, it should be noted that, in some cases, lower elastic modulus values are preferable for the concrete structures because of the flexibility that provides advantages to concrete in many cases. Especially for the lateral loading, modulus of elasticity may effect variation for the concrete behavior. Figure 2 illustrates the change in elastic modulus values for different codes used all over the world for a concrete having compressive strength of $36 \mathrm{MPa}$. The values used in the analyses has been changed between 21,200 MPa and 35,303 MPa.

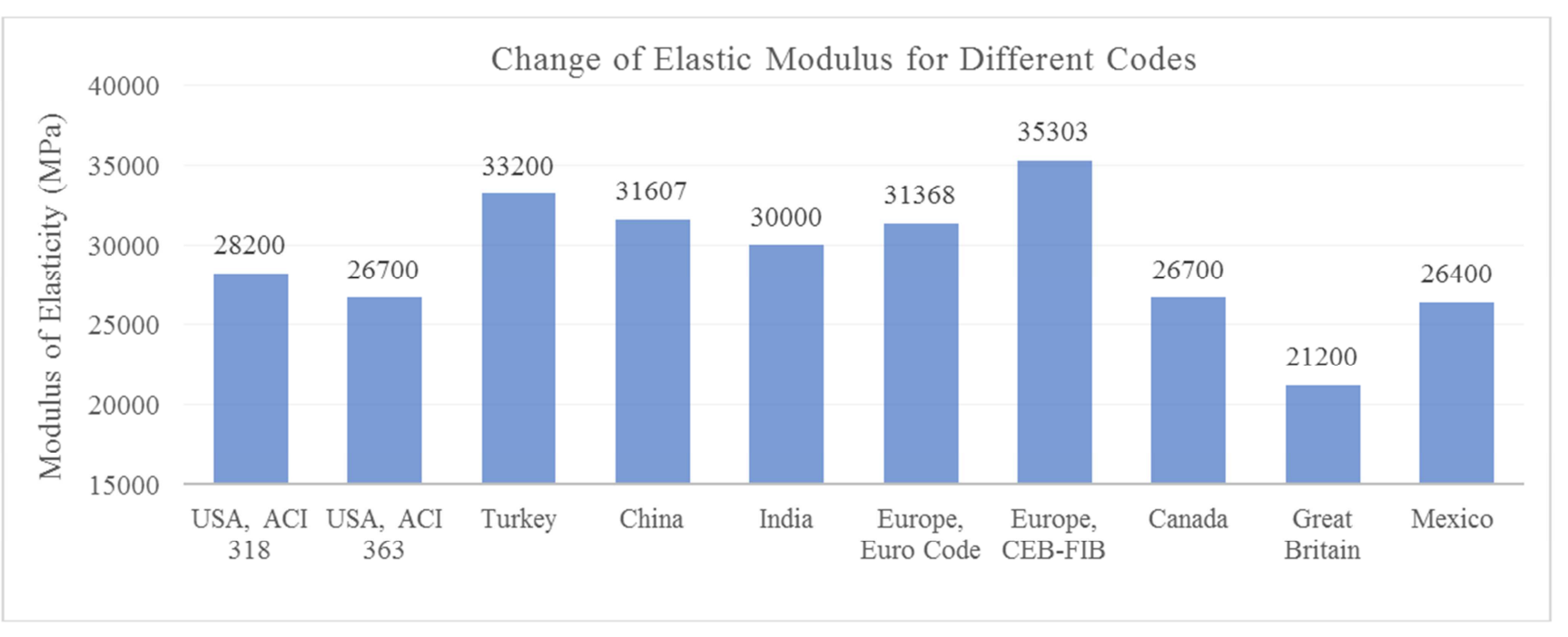

Figure 2. Modulus of Elasticity Values among Different Countries for $f_{c}=36 \mathrm{Mpa}$.

\section{Analysis of Short Concrete Beams with Different Modulus of Elasticity}

Since one of the objectives of this study was to investigate the effect of polymer coating on the elastic modulus for different regions, ten different codes commonly used were selected to satisfy this objective. Modulus of elasticity formulas are gathered from the USA-ACI 318, USA-ACI 363, Turkey, China, India, Europe, Euro Code, Europe CEBFIB, Canada, Great Britain, and Mexico. While the approximate maximum flexural load of $25 \mathrm{kN}$ for reference beam was achieved, it was $32 \mathrm{kN}$ for the beams coated with polymer A, $26 \mathrm{kN}$ for the beams coated with polymer B, $29 \mathrm{kN}$ for the beams coated with polymer C, $27 \mathrm{kN}$ for the beams coated with polymer $\mathrm{D}$. According to the maximum loads for different polymer coatings and compressive strength of $36 \mathrm{MPa}$, Table 3 was constructed. In Figure 3 through Figure 7, the maximum deflection for various countries are demonstrated. They reached by reference and polymer coated beams for different codes. Furthermore, the values are given for reference beam and polymer coated beams in Table 3 .

Table 3. Max Deflections of Reference and Polymer Coated Beams with Different Modulus of Elasticity.

\begin{tabular}{|c|c|c|c|c|c|c|}
\hline Maximum Deflections & Modulus of Elasticity & Reference Beam & Polymer A & Polymer B & Polymer C & Polymer D \\
\hline Design Codes & $\mathrm{E}(\mathrm{MPa})$ & $\Delta(\mathrm{mm})$ & $\Delta(\mathrm{mm})$ & $\Delta(\mathrm{mm})$ & $\Delta(\mathrm{mm})$ & $\Delta(\mathrm{mm})$ \\
\hline USA, ACI 318 & 28,200 & 0.038284 & 0.049175 & 0.039696 & 0.045228 & 0.041719 \\
\hline USA, ACI 363 & 26,700 & 0.040435 & 0.051937 & 0.041926 & 0.047769 & 0.044063 \\
\hline Turkey & 33,200 & 0.032518 & 0.041769 & 0.033718 & 0.038416 & 0.035436 \\
\hline China & 31,607 & 0.034158 & 0.043874 & 0.035417 & 0.040353 & 0.037223 \\
\hline India & 30,000 & 0.035987 & 0.046224 & 0.037314 & 0.042514 & 0.039216 \\
\hline Europe, Euro Code & 31,368 & 0.034417 & 0.044208 & 0.035687 & 0.040660 & 0.037506 \\
\hline Europe, CEB-FIB & 35,303 & 0.030581 & 0.039280 & 0.031709 & 0.036127 & 0.033325 \\
\hline Canada & 26,700 & 0.040435 & 0.051937 & 0.041926 & 0.047769 & 0.044063 \\
\hline Great Britain & 21,200 & 0.050925 & 0.065412 & 0.052803 & 0.060161 & 0.055495 \\
\hline Mexico & 26,400 & 0.040894 & 0.052527 & 0.042402 & 0.048311 & 0.044564 \\
\hline
\end{tabular}




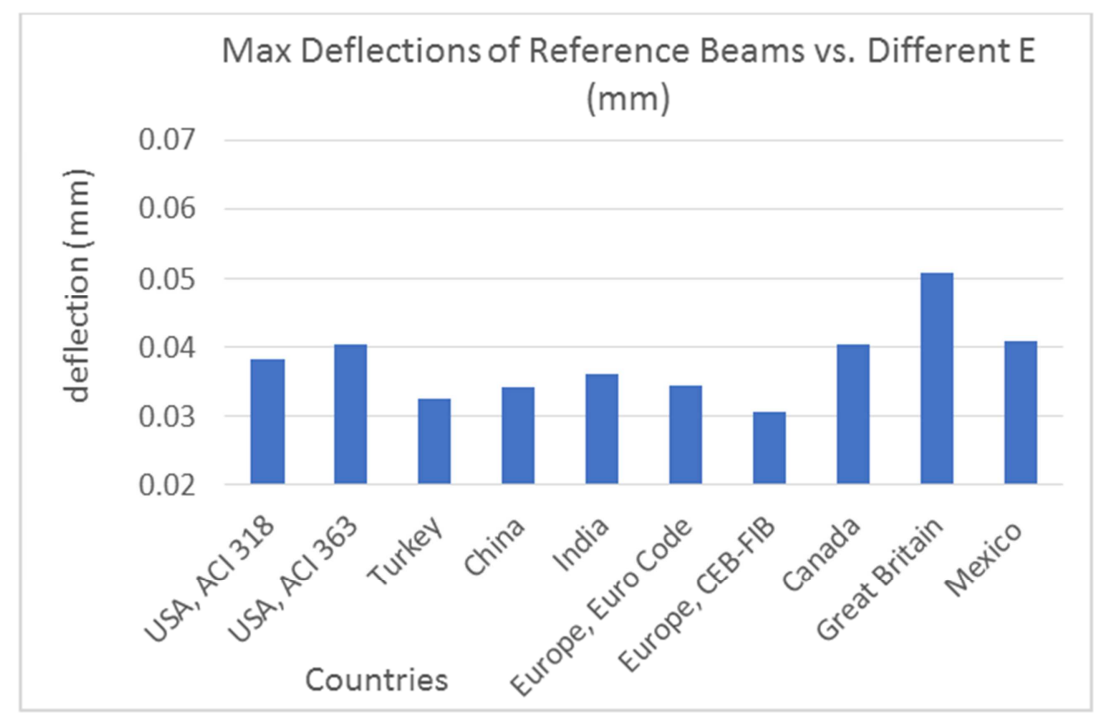

Figure 3. Reference Beam Deflection Chart.

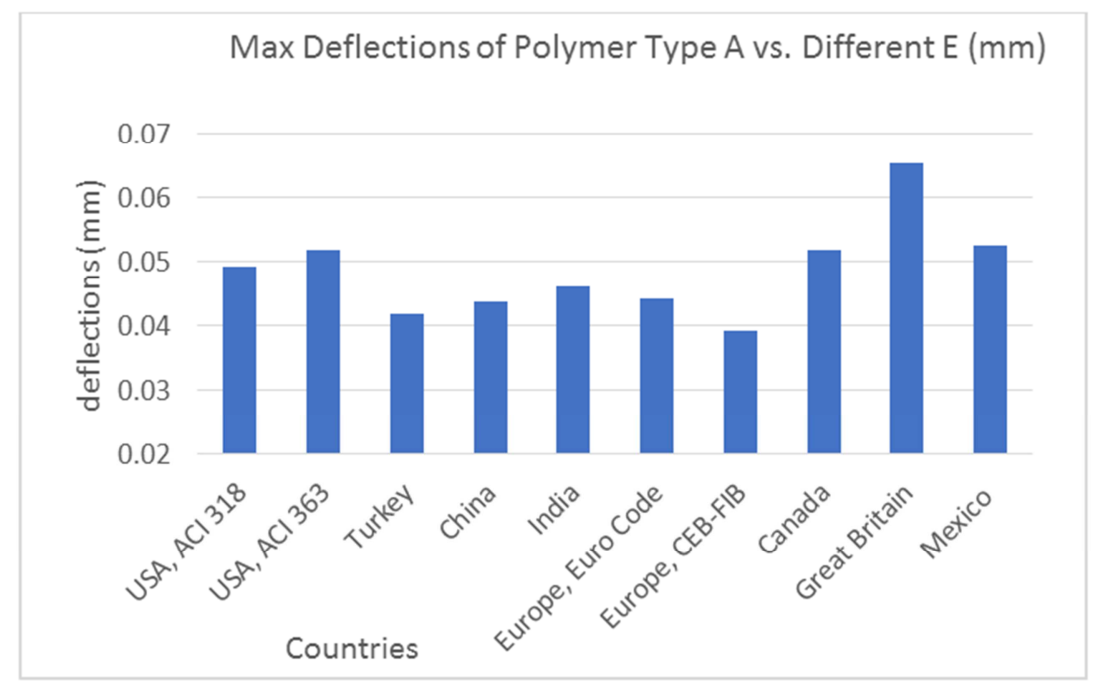

Figure 4. Polymer A Beam Deflection Chart.

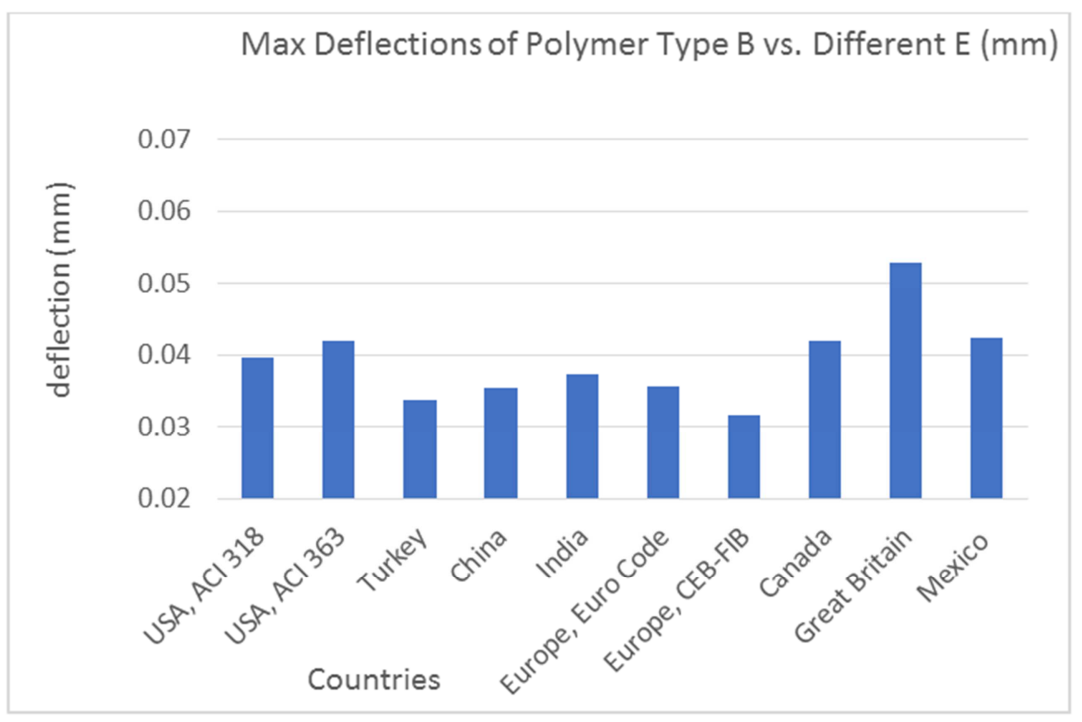

Figure 5. Polymer B Beam Deflection Chart. 


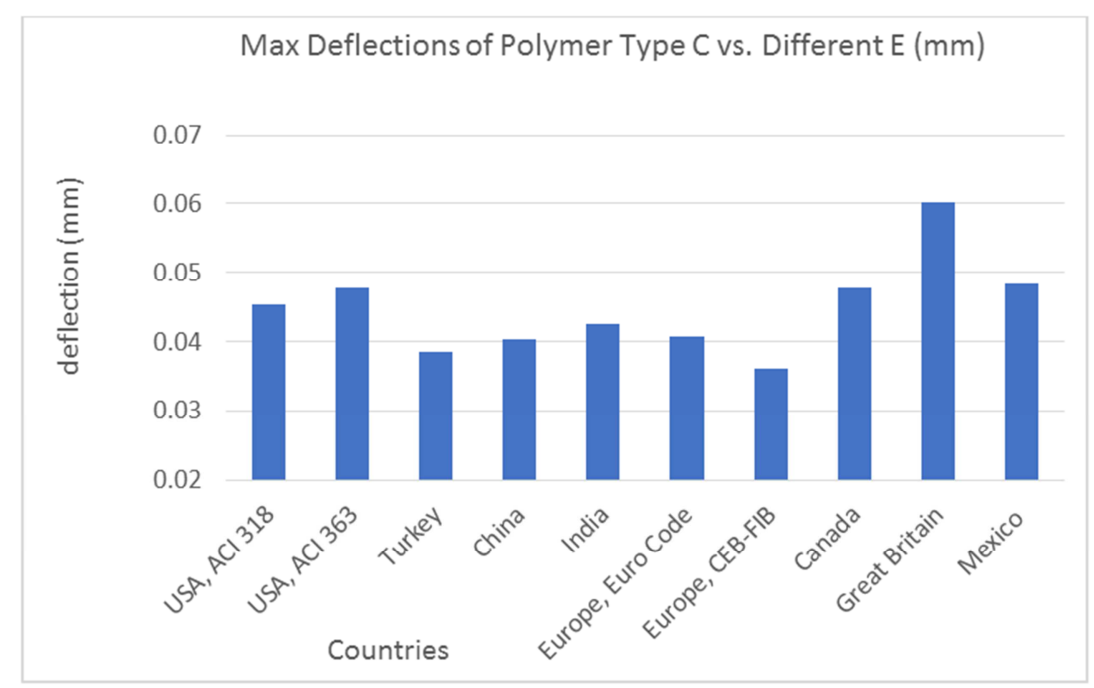

Figure 6. Polymer C Beam Deflection Chart.

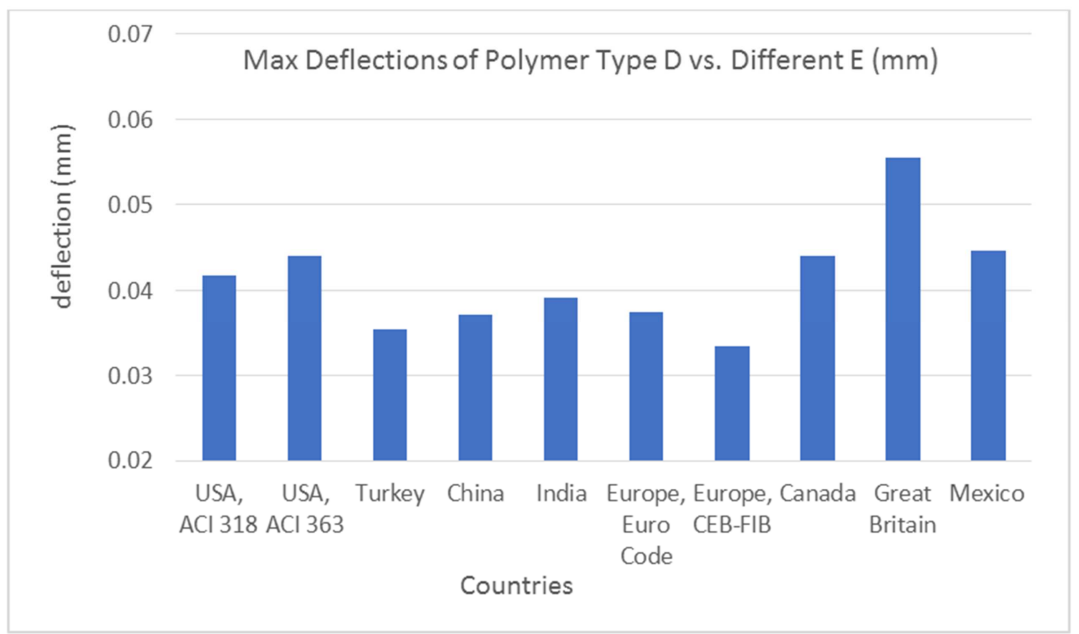

Figure 7. Polymer D Beam Deflection Chart.

\section{Comparison of Maximum Deflection and Elastic Modulus for Polymer Coated Beams}

The maximum deflections of the tested beams in the analyses have been calculated for a simply supported beam approach by using Equation 1 as given below. The dimensions of the beams were taken as $15 \mathrm{~cm} * 15 \mathrm{~cm} * 53 \mathrm{~cm}$ in the design setup for the research. The span length and moment of inertia for the beam was approximately $46 \mathrm{~cm}$ and $450 \mathrm{~cm}^{4}$, respectively. Figure 8 shows the theoretical test setup to find the flexural load that is required to apply the Equation 1 as given below. Since one of the aims of this study was to discover the effect of elastic modulus on the beam behavior, it was quantified by calculating the maximum deflection values for different codes from all over the world and various polymer-coated beams.

$$
\text { Deflection }(\delta)=\frac{P L^{3}}{48 E I}
$$

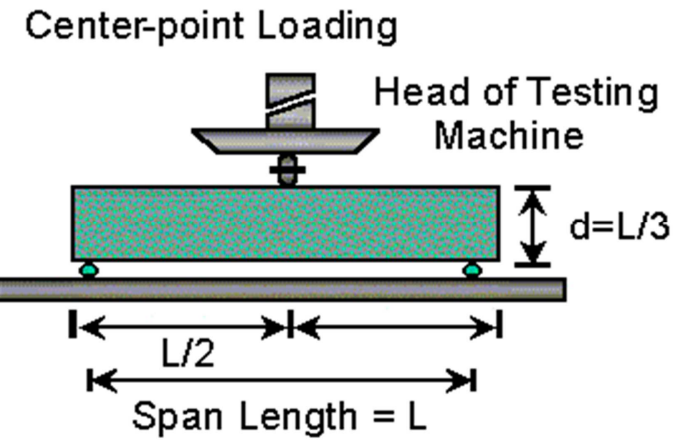

Figure 8. Three point (a.k.a, Center-point or Mid-point) Loading for Flexural Strength Test (A.P.C.A).

The deflection values calculated were presented in Table 3 for all the beams tested. The only variable in a specific code was the P- load at failure in Equation 1. Figure 9 illustrates the deformations sorted in an increasing manner for the same elastic modulus value, which uses the USA, ACI code with $\mathrm{E}_{\mathrm{c}}=28,200 \mathrm{MPa}$. The trend was shown with a linear line to provide a fundamental insight about the change of deflection per sorted modifications. 


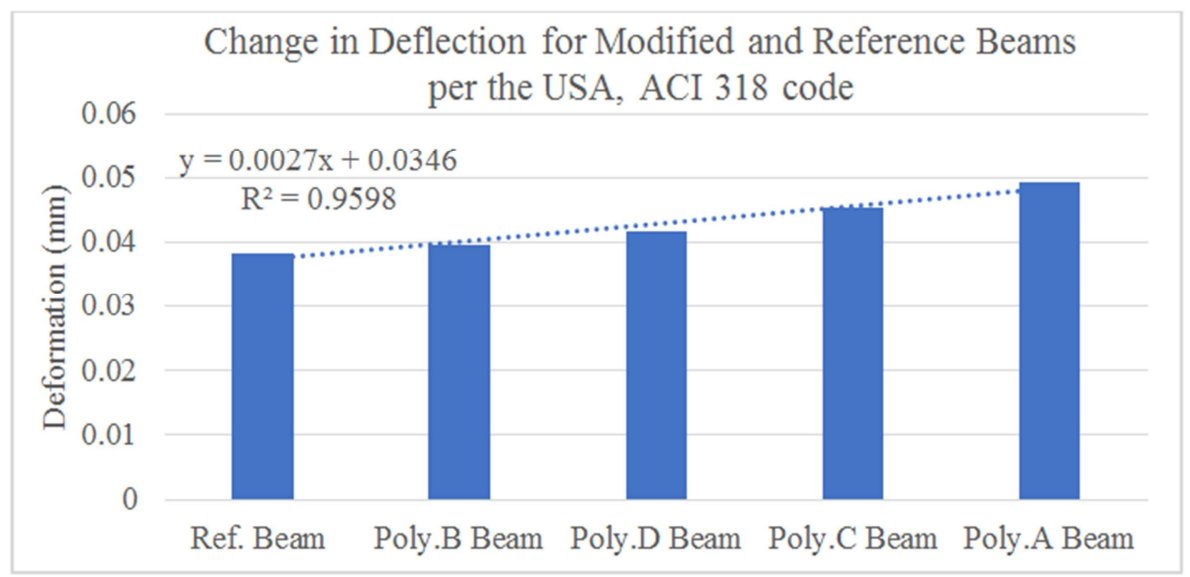

Figure 9. Change in Deflection vs Modification Type According to the USA, ACI 318 Code.

As following the deflection calculations according to various design codes for the beams, beams were investigated through deflection vs modulus of elasticity values. Therefore, Figure 10 through Figure 14 demonstrate the change in maximum allowable deflection as the elastic modulus of concrete alters for reference, polymer A-coated, B-coated, Ccoated, and D-coated beams, respectively. Figure 15 illustrates the maximum deflection versus elastic modulus change for all tested beams in a single graph. Data used in all the figures given here were obtained for a concrete mix design with characteristic compressive strength of $36 \mathrm{MPa}$ in the analyses carried out.

In the study, deflection calculations for beams have been performed assuming simply supported beam conditions were valid and using various design codes for elastic modulus values for the given cases for investigated beams with various polymer use.

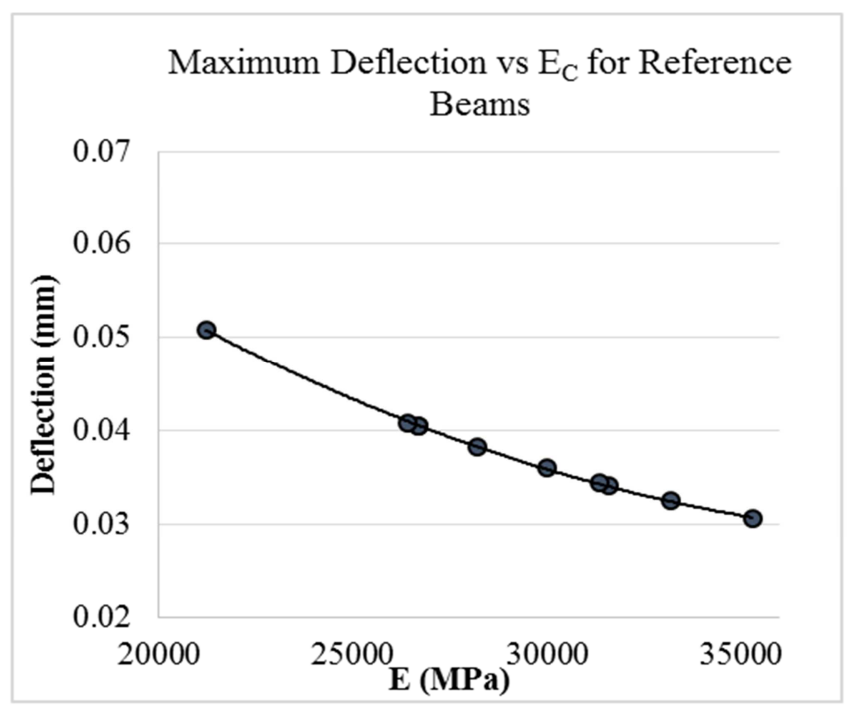

Figure 10. Deflection vs $E_{c}$ for Reference Beams.

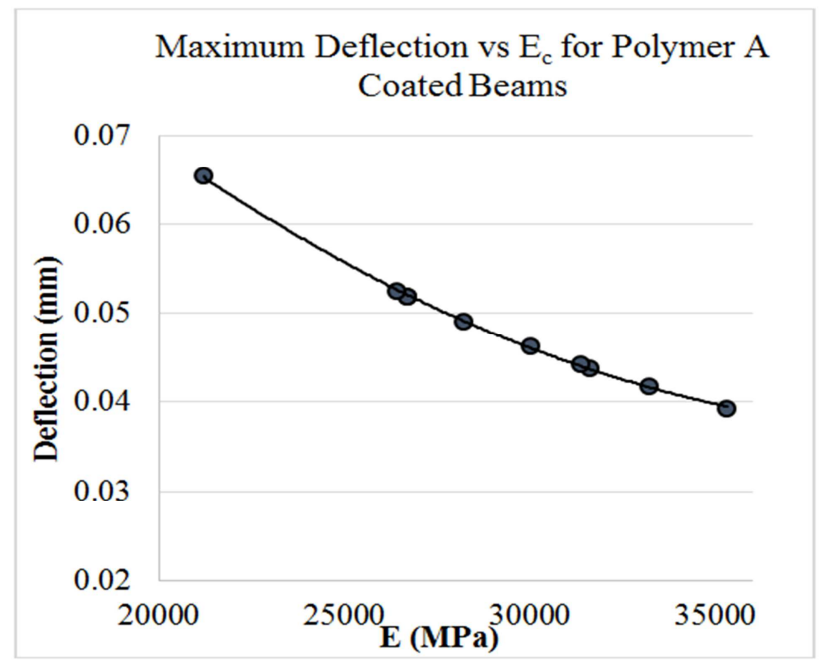

Figure 11. Deflection vs $E_{c}$ for Polymer A Coated Beams.

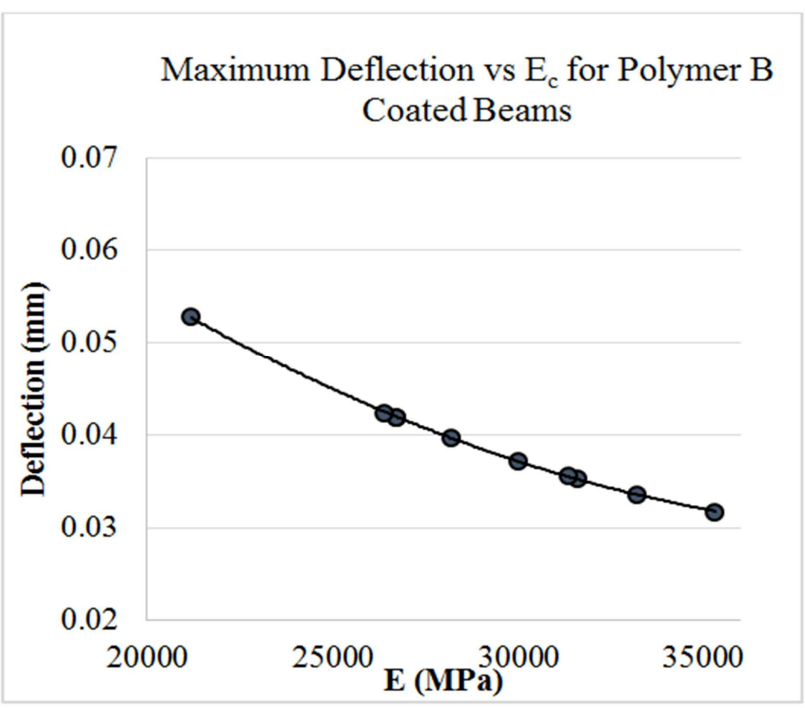

Figure 12. Deflection vs $E_{c}$ for Polymer B Coated Beams. 


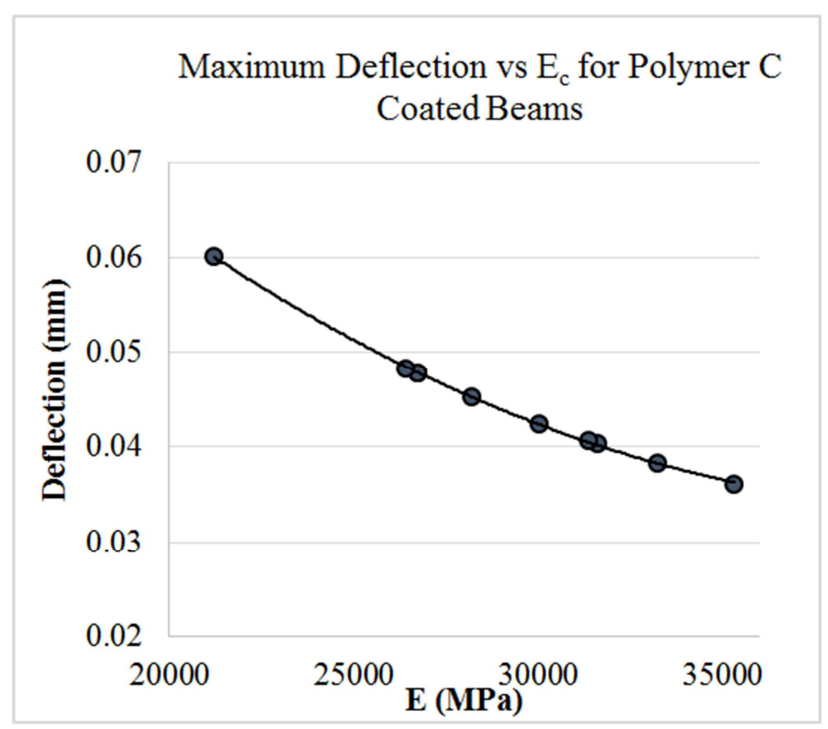

Figure 13. Deflection vs $E_{C}$ for Polymer C Coated Beams.

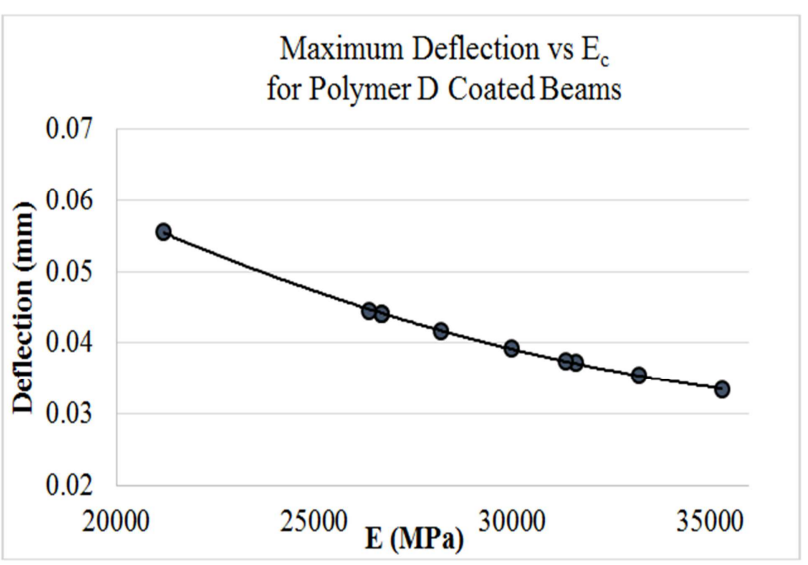

Figure 14. Max Deflection vs $E_{c}$ for Polymer D Coated Beams.

\section{Conclusions and Recommendations}

This study presented the findings for effect of polymer coating on the behavior of fiber reinforced short concrete beams. Structural behavior was quantified by means of elastic modulus and deformations for the beams. Elastic modulus empirical models were gathered from various codes of different countries from all over the world and unions of the word. Deformations were computed by using these elastic modulus values and the maximum loads the fibber reinforced short beams failed under testing. The results exhibit that any polymer coated beams performed better than the non-coated beams. Polymer A coated beams outperformed other coatings by failing at $31.96 \mathrm{kN}$ load and allowing a maximum deflection of $0.049175 \mathrm{~mm}$ according to the USA ACI 318 codes. The results can be put into order from the highest allowable deformation achieved to lowest one as polymer A, polymer $\mathrm{C}$, polymer $\mathrm{D}$, polymer $\mathrm{B}$, and non-coating. It also provides a clear trend for modification types per each code considered for the study. Especially in the construction site, proposed approach can simply be applied for increasing the strength and the durability for various environmental and loading conditions.

This study recommends further research to establish a universal coating method for increasing strength in beams, by standardizing one for creating more dependable strategy. Moreover, in the structural design of concrete structures, the effect of polymer amount on the coating can be considered as an increase in strength to find out an optimum polymer content, which yields higher allowable deformation for the concrete structures before fracture in various loading conditions. As various loading conditions lead various structural behavior, polymers may effect structural strength in good potential for structural members.

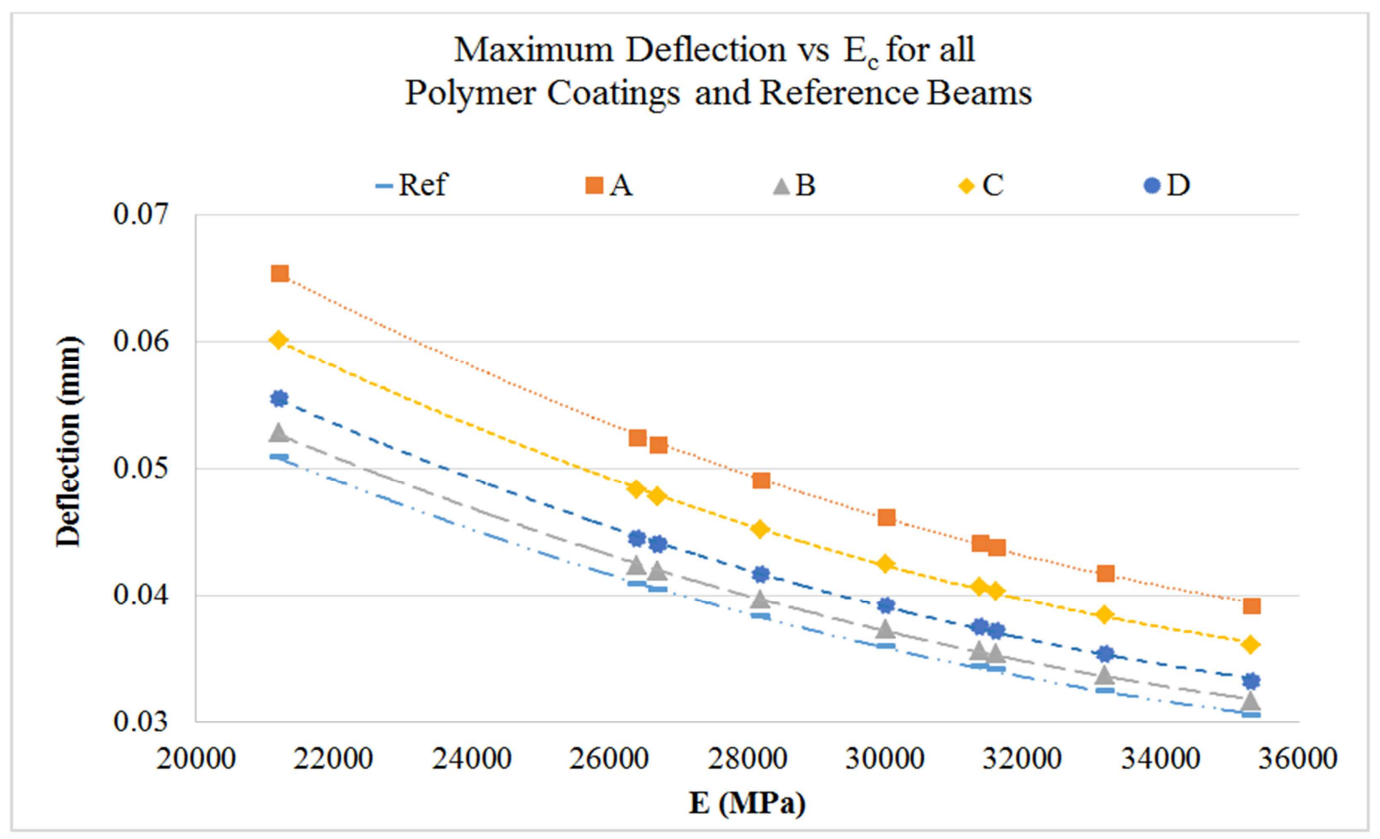

Figure 15. Comparison of Maximum Deflection vs Elastic Modulus for all Polymer Coatings and Reference Beams. 


\section{References}

[1] Illston J, and Domone, (2001), Construction materials: their nature and behaviour. CRC Press, $3^{\text {rd }}$ ed. London, U.K.

[2] Almusallam AA, Khan FM, Dulaijan SU, and Al-Amoudi OSB, (2003). Effectiveness of surface coatings in improving concrete durability. Cement and concrete composites, vol. 25(4-5), pp. 473-481. doi: 10.1016/S0958-9465(02)00087-2.

[3] Firmo JP, Arruda MRT, Correia JR, and Tiago C, (2015), Flexural behaviour of partially bonded carbon fibre reinforced polymers strengthened concrete beams: Application to fire protection systems design. Materials and Design, vol. 65, pp. 1064-1074, doi: 10.1016/j.matdes.2014.10.053.

[4] Wang K, (2004), Critical Issued of Sustainable development and emerging technology for "Green" Concrete. Proceedings of the International Workshop on Sustainable Development and Concrete Technology, Beijing, China, May-2004.

[5] WBCSD, (2009), Recycling Concrete Executive Summary by the Cement Sustainability Initiative. World Business Council for Sustainable Development. July 2009, www.wbcsdcement.org/recycling.

[6] ACI Committee 318-95, (1996), Building code requirements for structural concrete: ACI manual of concrete practice part 3: Use of concrete in Buildings-Design, Specifications, and Related Topics. Michigan: American Concrete Institute.

[7] Adam EG and Zurada JM, (2003), Data-driven linguistic modeling using relational fuzzy rules. IEEE Transactions on Fuzzy Systems, 11(1), 121-134, doi: 10.1109/TFUZZ.2002.803491.

[8] Al-Abdwais AH, and Al-Mahaidi RS, (2017), Bond properties between carbon fibre reinforced polymer (CFRP) textile and concrete using modified cement-based adhesive. Construction and Building Materials, vol. 154, pp. 983-992, doi: 10.1016/j.conbuildmat.2017.08.027

[9] Chen WF, Mehta HC, and Lu LW, (1974), Polymer impregnated concrete (pic) for building construction, Nov 1974, Fritz Laboratory Reports, Paper 2081, Civil and Environmental Engineering, Lehigh University.

[10] Benmokrane B, Chaallal O, and Masmoudi R, (1996), Flexural response of concrete beams reinforced with FRP reinforcing bars. Structural Journal, vol. 93(1), pp. 46-55.

[11] Tighiouart B, Benmokrane B, and Gao D, (1998), Investigation of bond in concrete member with fiber reinforced polymer (FRP) bars. Construction and Building Materials, vol. 12(8), pp. 453-462, doi: 10.1016/S09500618(98)00027-0

[12] Korkmaz KA, Tekeli H, Demir F, (2009), Determination of elastic moduli effects on storey-drifts by fuzzy logic algorithm, Journal of Civil Engineering and Environmental Systems, Volume 26, Issue 3.

[13] Vakhshouri B, (2018), Modulus of Elasticity of Concrete in Design Codes and Empirical Models: Analytical Study, Practice Periodical on Structural Design and Construction, Vol. 23, Issue 4, doi: 10.1061/(ASCE)SC.1943-5576.0000382.

[14] Haryanto Y, Hermanto N, Pamudji G, and Wardana KP, (2017), Compressive Strength and Modulus of Elasticity of Concrete with Cubed Waste Tire Rubber as Coarse Aggregates, Materials Science and Engineering 267 (2017).

[15] Kocab D, Kucharczykova B, Misak P, Zitt P, Kralikova M, (2016), Development of the Elastic Modulus of Concrete under Different Curing Conditions, 18th International Conference on Rehabilitation and Reconstruction of Buildings 2016. doi: 10.1016/j.proeng.2017.04.529

[16] Lee BJ, Kee SH, Oh T, Kim YY, (2017), Evaluating the Dynamic Elastic Modulus of Concrete Using Shear-Wave Velocity Measurements, Advances in Materials Science and Engineering. doi: 10.1155/2017/1651753.

[17] Lee YH, and Oh T, (2016), "The measurement of P-, S-, and $\mathrm{R}$-wave velocities to evaluate the condition of reinforced and prestressed concrete slabs," Advances in Materials Science and Engineering, doi: 10.1155/2016/1548215. 